\title{
Intercultural Conflict Among Exchange Participants of AIESEC in President University
}

\author{
Serdini Aminda Mazaid, Dindin Dimyati \\ President University \\ Jababeka Education Park \\ Cikarang Baru, Indonesia \\ dindin.dimyati@preseident.ac.id
}

\begin{abstract}
We live in a world where many cultures and languages merge together. It is concerned with how to develop relationships among people from different backgrounds in order to studying and working effectively in the different cultural background environment. Therefore, it is clear that intercultural conflict may occur during the communication process between people from different backgrounds. This research examines cultural differences which caused conflict on Morning Sunshine Project held by AIESEC in President University in 2016. The purposes of this research are to know what makes the intercultural conflict occur among Exchange Participants of AIESEC in President University and to know how the Exchange Participants of AIESEC in President University solve those intercultural conflicts. This research will employ qualitative methodology with descriptive qualitative approach. By using an online interview, data were collected from 5 Exchange Participants who come from 5 different countries. This research shows that intercultural conflict is not only about two parties with different cultural background who fight against each other but also about the uncomfortable feelings because of cultural differences and stereotype between individuals. To solve the intercultural conflict, participants chose collaboration, accommodation and avoidance as their conflict resolution.
\end{abstract}

Keywords-intercultural communication; conflict; cultural differences; conflict resolutions

\section{INTRODUCTION}

Nowadays, this world where we lived in is characterized by a growing number of connections resulting in communication between people with different languages and cultural background. All of us belong to many different cultural communities, whether they are related to family, occupations, nationalities, religion, social community, and so on. Each culture communicates and understand messages differently one to another. When individuals or groups from different cultural background meet, certain prejudiced that they have of each other influence their interactions, thus it may lead to misunderstanding and conflict. Conflicts are existing everywhere, it is happening all around the world at many different levels, whether it is interpersonal, social, national, and international [1]. Conflict is not just a matter of disagreement. Conflict between cultural groups can rise to a big issue that will echo across generations. Like relationships, conflict has different aspects and/or issues, it depends on whether it is between people of different cultures, different ethnic, political, or other groups.

This research will discuss about cultural differences which can cause conflict, that is when once a conflict occurs, cultural backgrounds and experiences influence how individuals deal with it. The researcher did an observation to the exchange participants of AIESEC in President University while they did a project in Indonesia [2]. After 6 weeks, the researcher found that there were some conflicts which were caused by cultural differences, background, lifestyles and communication styles among the exchange participants. Thus, the researcher was interested in exploring more about these topics.

With the case of Morning Sunshine project conducted by AIESEC in President University, the researcher analyzed the conflict that occurs between exchange participants during the activity. AIESEC is the world's largest global, non-political and not-for-profit youth organization which was founded in 1948, after the World Wide II, by a group of young European people (Belgium, Denmark, Finland, French, Netherlands, Norway, and Sweden). It was founded by students who were looking for a solution to the same problem. The goal was to ensure peace through mutual understanding of other cultures and countries. With the vision of "Peace and Fulfillment of Humankind's Potential", AIESEC is creating positive impact through three main attributes: leadership opportunities, international internships, and global learning environment. Morning Sunshine Project held by AIESEC in President University was one of the Global Volunteer program which aimed to encourage Indonesian students to build and develop their leadership potential. It was held on July, 18th 2016 August, 24th 2016 in Jakarta, Indonesia. 17 exchange participants from 12 different countries in 4 continents followed the project. Based on a 6 weeks observation, the researcher came up with 2 research questions: what makes the intercultural conflict occur among Exchange Participants of AIESEC in President University and how the Exchange Participants of AIESEC in President University solve those intercultural conflicts. In this research, the experiences and opinions of the participants will be emphasized.

\section{RESEARCH METHOD}

This study used qualitative methodology and descriptive approach. In this research, Exchange Participants' experiences in Morning Sunshine Project will be used to achieve the goal of 
this method. Qualitative research focuses on words rather than numbers and interested in deep exploration in order to provide rich, detailed, holistic description and explanation. The informants of this research are 5 exchange participants from Morning Sunshine project who have done their 6 weeks program in Indonesia. These 5 informants come from 4 different states and 5 different countries, which are Switzerland and Portugal as the representatives of Europe, Canada as the representative of America, Morocco as the representative of Africa, and Taiwan as the representative of Asia.The online interview lasted for 20-45 minutes long, according to their answers. The answer of the participants will help this research to give the information based on their own opinion, perception, and experience during their time in Indonesia. It will help the researcher to analyze and complete this research.

The researcher analyzed the data with four steps [3]. First step is transcribing the raw data which from audio data into text format. After that, researcher read the data in order to get a general sense from the data. Next step, the similar data were coded and categorized under a theme. The last step is interpreting the data by giving more insight and practices of intercultural communication.

\section{RESUlT AND DisCUSSION}

\section{A. Participants}

There are 5 participants of this research who were the Exchange Participants of Morning Sunshine Project held by AIESEC in President University. All of them come from different countries.

TABLE I. PARTICIPANT'S DATA

\begin{tabular}{|l|l|l|l|l|l|}
\hline No. & \multicolumn{1}{|c|}{ Name } & Age & \multicolumn{1}{|c|}{ Sex } & Origin Country & States \\
\hline 1. & AuroreBussot & 22 & Female & Canada & America \\
\hline 2. & Luciano F. Pinto & 21 & Male & Portugal & Europe \\
\hline 3. & Gloria Mihaljevic & 23 & Female & Switzerland & Europe \\
\hline 4. & El Mehdi Nounou & 23 & Male & Morocco & Africa \\
\hline 5. & $\begin{array}{l}\text { Chan Ken Leung } \\
\text { (Vincent) }\end{array}$ & 20 & Male & Taiwan & Asia \\
\hline
\end{tabular}

\section{B. Finding}

The intercultural conflict experience of 5 participants with different cultural background in a country that is far away from where they live become the significant of this research. Based on the online interview result, three of the participants who are Aurore, Luciano and Gloria said that they were so happy and excited when they met other Exchange Participants for the first time. They felt welcomed by the committees of the project and enjoyed the moments of being in the same place together with people from different countries. In contrast, El Mehdi and Vincent felt confused and really nervous. Vincent did not know how to start the conversation with new people from different backgrounds, while El Mehdi worried of saying something that would embarrass himself or the other Exchange Participants.

After some weeks of the project, all participants of this research knew each other more and adapted themselves to the situation quite well. Three of them, who are Luciano, Gloria, and El Mehdi chose to talk and engaged themselves more to other Exchange Participants who has similarities with them, either with those who spoke similar languages or came from similar cultures. They tried to find a balance through sharing and telling stories about their background, so that they could learn and develop their understanding about each other's culture in order to communicate effectively. The other ways were to give people chances to speak and communicate their views, and to treat others as you want to be treated. By that way, a harmony between some individuals from different cultural background could happen. Aurore started to notice the behavior and characteristic of some Exchange Participants. While, El Mehdi and Vincent adapted themselves well and they did not feel really nervous like before because they started to have a good relation with other Exchange Participants. El Mehdi said that it was hard at the beginning for him to be surrounded by other people who did not share the same culture but after couple of weeks, he could manage it.

Relating to the conflict they have seen and/or experienced during the project, all of participants mentioned the same conflict in Puncak in Exchange Participants and Organizing Committee bonding session. There were two girls from Europe who disagree with everyone's decision and kept insisting the committees to follow what they wanted when it was not possible to do in that moment, even after the committees and other Exchange Participants tried to explain the reasons. A long argument was happened, some people were shouted, and still, those two girls did not understand the situation. This conflict happened where one of those two girls, who came from Czech Republic was saying something which consider inappropriate and rude for some cultures, including Indonesia. She said "sorry for being bitchy, but you cannot always follow the OC!" (OC: Organizing Committee). Some participants of the research gave explanation and insight regarding the issue.

Other than this, because some of them felt that they didn't experience significant conflict in personal, they preferred to share some cultural differences in the project. Vincent shared his uncomfortable feeling when he was having a teaching session in one of Junior High School 1 in Jakarta. There were some students who laughed at his Chinese accent that might be sounds funny. Similar with Vincent, El Mehdi also shared his problem about his English-speaking ability. He was afraid that the students in the school could not get his message clearly, because he spoke English with a bit of Arabian accent. However, after couple of weeks they managed it well because their English have improved. There were also some little conflicts happened because of miss communication, cultural differences and language problem.

Three of Exchange Participants had quite similar ways to resolve conflict they have experienced. In short, Aurore, Gloria and Vincent chose to speak up the problem and find a balance. Aurore thought that got back to her comfort zone, in the other words is to find people who were the same with her, was the easiest way to solve the conflict. Vincent said that it is important to figured out the problem and seek a balance. By that way, people could meet the interest of two sides without hating each other. Meanwhile, Gloria perceived that in order to solve a conflict, people need to understand the other person first. She learned some values during her volunteering experience, which are to step back and don't react impulsively. 
Based on Luciano's opinion, 'walk away' was the best solution for him to solve the conflict when he felt that he has nothing common with the person. Meanwhile, to solve their language problem, El Mehdi and Vincent got help from some committees and volunteer of the project.

\section{Discussion}

1) What makes the intercultural conflict occur among Exchange Participants of AIESEC in President University?

Through the 5 participants of Morning Sunshine Project experiences and explanation, it found that three main reasons for the emergence of intercultural conflict which happened between Exchange Participants were language, cultural differences, and stereotype. They noticed some cultural differences which existed among Exchange Participants, as well as some differences from their culture and Indonesian culture. Through the data collection, each participant has different problem and/or conflict towards it. All of participants conflict experiences are related to Relational Dialectic Theory which argues that there will always be a contradiction in a communication process and that change and the opposite needs are inevitable [4].

There are two participants who were experienced certain conflict because of their language problem. Cultural distance is greater when people speak different languages [5].

Vincent and El Mehdi's answers explained that they have difficulties in communicating with people from different countries because they have limitation of English skills. El Mehdi, who is Moroccans and Vincent who is Chinese perceived language as a big challenge for them in the beginning because they couldn't speak as fluent as the other Exchange Participants which mostly European. The fact that language is used to convey and to understand information leads to an explanation that it is almost certain that in the process of dealing between two partners speaking in different language, misunderstanding or conflict might be happened which caused by rather the inaccurate translation or the case of using another (third) language which familiar for both parties. In this case of research, is English.

Several cultural differences were found by the participants of this research during the project as the cause of intercultural conflict. Some of them just noticed the differences, some others experienced it directly. However, all participants were respect the cultural difference and believed that none of the cultures is the best. Aurore added about her experienced of being in the same group with Germans and Americans. "It was challenging in the way to prepare our presentation. Cultural aspects came back easily. German and American EP was really organized and managed his team efficiently. Moroccans was considering his team and cherished them with greetings." Her answer is supporting [5], which argues that there are many similarities between German and American cultures because they share, to some extent, a common European Heritage. Germans like to be well prepared for a meeting which often translates into lack of spontaneity. But her answer also shows a contrary result toward previous finding, stating that South African should keep their presentation short and to the point and filled with specific ideas.
Some cultural differences and similarities also shown from the side of religion as it is one of the culture's element [6]. El Mehdi, the Moroccans participants shared that their culture is totally different compared to Europe. Morocco is a Moslem country which have a specific traditions and strict rules to respect God (praying, no alcohol consumption, etc.). But he did not have a lot of difficulties to get used to the Indonesian style because the majority people are also Moslem. The cultural differences also shown from their eating habits. One of participants, Luciano, had an uncomfortable experience relating to this issue. As a European, he felt irritated when he was eating with the Chinese Exchange Participants because they made noises when chewing their food. For Chinese people, to make noises while eating is a sign of enjoying the food. It shows as an appreciation toward the delicate cuisine. Eating behavior has continuity, that wherever people moving to other regional or countries, they will continue keeping their tradition eating habits. Luciano explained that to make noises while eating is a sign of impolite and rude in Europe. Therefore, they are taught to always keep their mouth closed while eating.

Stereotype and prejudices were found during the project which becoming the factor of the emergence of conflict. Through the answers of the interview, Luciano, the participants from Portugal mentioned that there is a prejudice in Europe that people from the South are lazy, dumb, and don't like to work. The Eastern Europeans participants in the project (Czech Republic, Hungary, Poland and Slovakia) were talked to the Southern Europeans (France, Italy, Portugal and Spain) by assuming that prejudice, and he hated it. Luciano's case support the explanation that there are number of ways in which stereotypes are harmful [7]. The stereotype also proved in the conflict between Exchange Participants and the committees in Puncak, as mentioned in the previous chapter. The girls who complained, insisted, and responded to the situation with inappropriate words were both come from the Eastern European. Similar to Luciano, Gloria said that Southern Europeans are more positive, complain less, and laugh more compared to Eastern Europeans. That is why during the project, the group was a bit divided while in the other time were very united.

2) How the Exchange Participants of AIESEC in President University solve those intercultural conflicts?

Based on the result of online interview with the participants, the researcher found supportive findings related to Intercultural Conflict Management which are accommodation, collaboration and avoidance. It started with the accommodation style, when people scarify one need in order to please other parties and fulfill their needs [8]. They described that accommodation is a form of dealing with conflict where one attempts to satisfy the other person's desires. This conflict resolution was used by Vincent when he was having a conflict with his team in Thousand Island. Vincent found that accommodation was his best way to solve the conflict as he did what other Exchange Participants suggested him to do which were to speak louder, be cheerful and did more things to strengthen the bond between him and the students in the school. In order to keep the peace, therefore he accommodated the need of other parties and set aside his introvert personalities 
with trying to stepped out from his comfort zone. Moreover, harmony is an important thing in Chinese culture.

Different with Vincent, three of participants chose to seek similarity and find balance as their way to solve the intercultural conflict. They argue that there is a need to find a middle way, a balance, where people are sure to express what they want without offending or insulting someone else. That when communicate with people from different backgrounds, the individuals need to find a way to say things that are acceptable anywhere and meet the interest of two parties. Therefore, they chose collaboration style. Collaboration is the idea that all parties work together to resolve conflict. It is the matter of finding creative solution to satisfy all parties' concern. None of the individuals wanted to give up their selfinterest, so they decided to address the conflict directly, dig onto the issues and identify the underlying concerns. This conflict solution takes time and fosters respect, trust, and builds relationship. The need to speak up the problem was important for them to argue each member's point of view, so that it will draw a global picture of the team goals and expectation in order to improve the individuals.

In contrast, one other participant shared that walking away or avoidance is the best solution to solve his conflict. Neither accommodation nor collaboration style were worked for him. After he tried to talk to the person he had a conflict with and deliver his interest in a best way he could, the person did not respond him in a good way, and the more he tried to speak the more their personalities clashed. The more they spent time talking, the more they did not like each other and see each other negatively. At the end, instead of fighting against, he chose to walk away and keep the distance. Avoidance is characterized by deliberately ignoring or withdrawing from a conflict rather than facing it. It comes from an assumption that a conflict will disappear if it is just ignored [8, 9, 10]. However, there are situations where avoidance is appropriate when individuals need time to think of how to respond the conflict, to cool off the heat or when someone perceived that confrontation will hurt a working relationship.

\section{CONCLUSION}

Through the above analysis and research, it concluded that intercultural conflict is not only the matter of two cultures with different backgrounds which fighting against each other. However, intercultural conflict can also about the uncomfortable feelings and the uncertainty that the participants had when they communicate to each other due to the differences of culture, language, religion, and the stereotype that they hold of each other. When conflict happens, the participants have different way to solve it. No conflict style is right or wrong. The participants chose their best way which worked for them at the moment based on the conflict they have experienced, and with whom they had a conflict. To solve the problem, most of participants chose collaboration as the conflict resolution, and the rest chose accommodation and avoidance style. Collaboration style was the most effective way for them to solve the conflict because each of participants have strong interest or needs. Finding balance between different needs was important for the participants which could be achieved by addressing the problem, understanding the views of others and seeking the best solution that is acceptable for both parties. The participants worked together to have a winwin solution toward the different needs and interest.

It is suggested for the exchange participants to increase their cultural awareness before entering a new culture. It would be great if individuals try to practice the behaviors of the host culture in a simulated host culture environment. Besides, learning and gathering information about the culture are also important to reduce anxiety, fear or uncertainty that might happen in some situations in the host culture. Through those experiential learning process, it is assumed that participants will know the value system and appropriate behavioral system of the host culture and feel more comfortable in living, working, or interacting with people.

\section{REFERENCES}

[1] J.N. Martin and T.K. Nakayama, Intercultural Communication in Contexts. 5th Ed. New York, NY: McGraw-Hill, 2010.

[2] AIESEC. Our Identity. [In AIESEC www-pages]. From: http://www.aiesec.org/about/our_identity

[3] J.W. Creswell and W.E. Hanson, V.L. Clark Plano and A. Morales, Qualitative research designs: Selection and implementation. The counseling psychologist, 35(2), 2007.

[4] L.A. Baxter and B.M. Montgomery, Dialectical Approaches to Studying Personal Relationships. Mahwah, NJ: Lawrence Erlbaum Associates, 1998.

[5] L.A. Samovar, R.E. Porter, E.R. McDaniel and C.S. Roy, Intercultural communication: A reader. Boston: Wadsworth Cengage Learning, 2014.

[6] L.A. Samovar, R.E. Porter, E.R. McDaniel, and C.S. Roy, Communication between cultures. Boston: Wadsworth Cengage Learning, 2015.

[7] F.E. Jandt, An introduction to intercultural communication: Identities in a global community. Thousand Oaks: Sage Publications, 2017.

[8] J.G. Oetzel, Intercultural communication: A layered approach. New York: Vango Books, 2009.

[9] G.A. Barnett and M. Lee, Issues in intercultural communication research. In Gudykunst, W. B. \& Mody, B. (ed.) Handbook of international and intercultural communication. 2nd edition. Thousand Oaks: Sage Publications, 2002.

[10] I.S. Jacobs and C.P. Bean, "Fine particles, thin films and exchange anisotropy," in Magnetism, vol. III, G.T. Rado and H. Suhl, Eds. New York: Academic, 1963, pp. 271-350. 